\title{
RENCANA AKSI PEREMAJAAN PERKEBUNAN KELAPA SAWIT RAKYAT KELOMPOK TANI DAN KUD BUKIT JAYA DI KABUPATEN DHARMASRAYA PROVINSI SUMATERA BARAT
}

\author{
Melinda Noer*), Ira Wahyuni Syarfi, dan Rafnel Azhari \\ Jurusan Sosial Ekonomi, Fakultas Pertanian Universitas Andalas \\ ${ }^{*}$ Email: melindanoer@agr.unand.ac.id
}

\begin{abstract}
ABSTRAK
Perkebunan kelapa sawit di Propinsi Sumatera Barat sudah memasuki umur tanaman yang tidak ekonomis lagi untuk terus diusahakan, sehingga perlu diremajakan untuk mewujudkan pembangunan perkebunan berkelanjutan. Penanaman kembali (replanting) untuk tanaman yang berumur $>25$ tahun sudah harus dilakukan. Kabupaten Dharmasraya sedang mempersiapkan masyarakat pekebun kelapa sawit untuk program replanting tanaman kelapa sawit. Namun pada banyak kondisi perkebunan rakyat, koperasi petani yakni KUD menjadi penting untuk dikembalikan fungsi dan perannya dalam replanting, sehingga KUD perlu diberdayakan. KUD Bukit Jaya adalah satu-satunya KUD Perkebunan Plasma PIRTrans di Kab. Dharmasraya yang masih aktif dan antusias untuk melakukan replanting, namun anggotanya belum melaksanakan replanting. Permasalahan KUD Bukit Jaya adalah belum mendapatkan akses bantuan hibah dana replanting, memiliki dana Idapertabun sebagai modal awal replanting namun belum diterima, dan KUD belum memiliki rencana aksi untuk replanting. Kegiatan ini membantu KUD Bukit Jaya untuk menyusun rencana aksi replanting tanaman kelapa sawit di wilayah kerjanya, memfasilitasi akses bantuan hibah dana replanting dan Idapertabun. Hasil kegiatan ini, telah membuat KUD Bukit Jaya memiliki rencana aksi replanting, terbukanya akses untuk pendanaan melalui hibah dana replanting dan bantuan bibit unggul.
\end{abstract}

Kata Kunci: tanam ulang, kebun kelapa sawit, rencana aksi koperasi.

\section{Replanting Cctions of Palm Oil between Society, Farmer Groups, and Kud Bukit Jaya In Dharmasraya District, West Sumatera Province}

\begin{abstract}
Palm Oil Plantation in West Sumatra is entering the unproductive period since the plant has been over than 25 years and need to be replanted in the form of sustainable plantation development. Dharmasraya District is currently preparing the small-holders farmer to implement palm oil replanting program. However, farmer co-operative namely KUD in many cases of is a fundamental variable which determines replanting implementation. KUD have to be functioning and taking the role in replanting prepreparation and its implementation as well. For that reason, empowerment of KUD is desirable. KUD Bukit Jaya is the one among others that still exist in Plasma Trans-Plantation in Dharmasraya, which is very enthusiastic to replanting program. However, KUD members still could not afford to execute replanting. The problems of KUD Bukit Jaya in relation to replanting are had no fund available for replanting start with and has no action plan yet. KUD has plantation insurance in Idapertabun program but still, need some technical administration process to be handled. This academic project for the community has facilitated KUD Bukit Jaya to access fund from BPDPKS and Idapertabun, besides KUD action plan for replanting has also been approved by KUD members.
\end{abstract}

Keyword: replanting, oil palm plantations, cooperative action plans 


\section{PENDAHULUAN}

Perkebunan kelapa sawit di Indonesia sudah memasuki umur ekonomis (periode tidak produktif) sehingga tidak efisien lagi untuk diteruskan dalam konsep pembangunan perkebunan berkelanjutan. Produktivitas yang selalu menurun akan berdampak kepada jumlah produksi yang selalu menurun dan pendapatan usahatani yang berkurang. Untuk itu, perlu dilakukan penanaman ulang (replanting) tanaman kelapa sawit. Program replanting ini sudah ditetapkan sebagai program nasional, termasuk perkebunan kelapa sawit rakyat di Propinsi Sumatera Barat.

Kabupaten Dharmasraya merupakan salah satu kebupaten yang memiliki jumlah lahan perkebunan kelapa sawit terluas kedua di propinsi Sumatera Barat, setelah kabupaten Pasaman Barat (BPS, 2018; Ditjen Perkebunan, 2014). Kabupaten Dharmaraya sejak tahun 2017 sedang melakukan persiapan replanting dan sudah membentuk Tim replanting di tingkat Kabupaten pada tahun 2018. Peremajaan kebun kelapa sawit di kabupaten ini juga sejalan dengan rencana pembangunan jangka menengah (RPJM) Daerah tahun 2016-2021.

Koperasi Unit Desa (KUD) diperlukan sebagai wadah kerjasama petani dan kelompok tani dalam pengusahaan perkebunan kelapa sawit. KUD berperan dalam memfasilitasi petani dan kelompok tani untuk menyusunan rencana kerja (rencana aksi) kelompok tani dalam rangka perencanaan penanaman kembali (pre-replanting), pelaksanaan replanting, dan setelah replanting, yakni dalam hal pengolahan dan pemasaran hasil kebun kelapa sawit (Syarfi dan MNoer, 2017). KUD menjadi penting untuk diberdayakan dengan membantu menyusun rencana aksi replanting kebun kelapa sawit. Pemberdayaan KUD membutuhkan kemampuan anggota dan pengurusnya untuk saling menghargai, kemampuan merefleksi secara kritis, memberi perhatian, dan peran serta semua potensi yang dimiliki. KUD membutuhkan nilai fundamental yang menjadi jiwa sebuah koperasi berupa kepercayaan dan keinginan untuk memajukan usaha bersama, nilai kebaikan untuk mencapai perbaikan, tanggung jawab individu dan kelompok, kemauan untuk menolong diri sendiri, serta sufat persaudaran dan kekeluargaan (Hatta, 2000).

Kontribusi penting dari kegiatan ini, selain tersusunnya rencana aksi replanting KUD, adalah tumbuhnya kembali kesadaran petani untuk mengembangkan lagi kelembagaan Koperasi yang berdaya melalui partisipasi aktif anggotanya, terbangunnya kelompok tani dan/atau gabungan kelompok tani yang kuat sebagai pelaku pembangunan perkebunan kelapa sawit rakyat, serta berfungsinya Koperasi (KUD Bukit Jaya) untuk mensukseskan kegiatan peremajaan (replanting) tanaman kelapa sawit rakyat di kabupaten Dharmasraya. Diharapkan kegiatan peremajaan kebun kelapa sawit oleh KUD Bukit Jaya ini dapat menjadi contoh kegiatan pemberdayaan kelembagaan petani dan koperasi untuk mewujudkan pembangunan perkebunan kelapa sawit berkelanjutan di Propinsi Sumatera Barat.

Perencanaan aksi peremajaan perkebunan ini, kelompok tani dan koperasi perlu didampingi dalam membangun kerjasama pembangunan kebun kelapa sawit dengan lembaga yang akan menjadi mitra kerjanya. Lembaga mitra tersebut dapat terkait dengan lembaga pembiayaan (Asuransi, Perbankan), lembaga teknis budidaya dan penyediaaan input (instansi teknis pemerintah atau perusahaan), serta lembaga pemasaran (jaminan pasar TBS oleh Perusahaan pengolah) dan lainnya. 
Permasalahan KUD Bukit Jaya adalah kelompok tani dan Koperasi belum menyusun rencana aksi peremajaan kebun kelapa sawit di wilayah kerjanya. Penanaman ulang atau replanting seharusnya sudah dilakukan karena tanaman kelapa sawit telah melewat umur 25 tahun, dan produktivitas yang rendah akan tidak menguntungkan untuk dipertahankan Pahan, 2008). Dengan demikian, urgensi kegiatan ini adalah pentingnya membantu petani kelapa sawit rakyat melalui kelompok tani dan KUD untuk menyusun rencana aksi peremajaan kelapa sawit dan meningkatkan aksesibilitas kelompok kepada faktor sosial, ekonomi, dan teknis agar terlaksana kegiatan peremajaan tanaman kelapa sawit yang terencana dengan baik. Petani dan keluarga juga perlu merencanakan kegiatan ekonomi yang akan menjadi sumber pendapatan rumah tangganya sampai tanaman sawit dapat memberikan hasil panen. Kapasitas kelompok tani dan koperasi dengan demikian perlu ditingkatkan melalui kegiatan pendampingan penyusunan rencana aksi peremaaan kebun sehingga dapat membangun kemitraan kembali dengan perusahaan inti, lembaga perbankan dan lembaga penyedia saprodi (input), serta menghubungannya dengan tugas dan fungsi Organisasi Penyelenggara Daerah (OPD) terkait melalui penyuluhan dan bimbingan teknis budidaya tanaman sawit, mulai dari pengolahan lahan, penyediaaan bibit dan saprodi lainnya, pemeliharaan tanaman, serta pemasaran hasil panen.

Tujuan ini adalah membantu kelompok tani dan KUD Bukit Jaya menyusun rencana aksi peremajaan kebun kelapa sawit di wilayah kerjanya di Kabupaten Dharmasraya. Secara langsung mendorong dan menghidupkan kembali semangat kerjasama Kelompok tani dan KUD dengan lembaga mitra yang ada. Selanjutnya, secara tidak langsung diharapkan kegiatan ini akan membantu mensukseskan kegiatan peremajaan perkebunan sawit di Kabupaten Dharmasraya dan menjadi proyek percontohan untuk kegiatan peremajaan kebun sawit rakyat di Propinsi Sumatera Barat. Dengan pendekatan pembangunan perkebunan kelapa sawit berkelanjutan, diharapkan petani sawit menjadi lebih bergairah untuk mengelola kebun sawitnya dengan baik.

\section{METODE}

Metoda kegiatan yang digunakan adalah metoda diskusi dan wawancara. Diskusi dilakukan dalam bentuk diskusi kelompok dengan topik fokus pada persiapan replanting kebun kelapa sawit. Metoda wawancara digunakan untuk emndapatkan informasi dan gambaran yang lebih rinci dari informan kunci dalam persiapan replanting. Informan kunci dimaksud adalah Pengurus KUD, Badan Pengawas KUD, Kepala Bidang Ekonomi Bapppeda Kabupaten Dharmasraya, Dinas Koperasi Perdagangan dan Industri (Koperindag) Kabupaten Dharmasraya, Dinas Pertanian Kabupaten Dharmasraya, serta Perusahaan inti (PT. SAK).

Waktu Pelaksanaan kegiatan pada bulan April s/d November tahun 2018, dengan rincian kegiatan menyusun rencana kegiatan, mengkoordinasikan dengan pihak2, sosialisasi / pertemuan awal dengan kelompok petani sasaran dan KUD, serta melaksanakan kegiatan pendampingan penyusunan rencana aksi. Lokasi kegiatan di Kecamatan Tiumang Kabupaten Dharmasraya Propinsi Sumatera Barat.

Mitra yang terlibat sebagai berikut:

1. Kelompok tani kelapa sawit rakyat (juga sebagai anggota KUD Bukit Jaya): berkontribusi memberikan data dan informasi potensi sumberdaya yang dimiliki 
dalam rangka kegiatan peremajaan kebun kelapa sawit dan menyusun rencana aksi peremajaan kebun kelapa sawit.

2. KUD Bukit Jaya berkontribusi dalam memberikan informasi dan potensi sumberdaya yang dimiliki dalam rangka mengidentifikasi kebutuhan persiapan peremajaan kebun kelapa sawit sebagai wadah dan mitra kelompok tani dan menyusun rencana aksi peremajaan kebun kelapa sawit.

3. Badan Perencanaan dan Penelitian Pengembangan Daerah Kab. Dharmasaya berkontribusi sebagai koordinator dalam keterlibatan Organisasi Perangkat Daerah di lingkungan Kabupaten Dharmasraya dalam peremajaan kebun kelapa sawit.

4. Dinas Koperasi Kabupaten Dharmasaraya berkontribusi memberikan pedoman teknis sekaligus sebagai pendamping dalam menyelesaikan persoalan prinsipal dan teknis tata kelola administratif, sehingga kelompok dan KUD Bukit Jaya dapat menyusun rencana aksi dan melaksanakan peremajaan kebun kelapa sawit.

5. Dinas Pertanian, sub bidang Perkebunan berkontribusi dalam menyiapkan petani dalam hal penyiapan lahan, penyediaan sarana produksi, teknik budidaya, menetapkan pola replanting, dan pemeliharaan tanaman.

6. Perusahaan inti PIR-Trans berkontribusi memfasilitasi petani melalui kelompok tani agar memiliki kemampuan dan menguasai teknik budidaya peremajaan tanaman, mulai dari penyediaan bibit, pemeliharaan dan panen / pasca panen.

\section{HASIL DAN PEMBAHASAN}

Permasalahan yang ditemukan di KUD Bukit Jaya dalam rangka replanting tanaman kelapa sawit adalah sebagai berikut:

1. Petani anggota Kelompok tani yang merupakan anggota KUD ada yang belum bergabung dengan Koperasi Perkebunan, khususnya KUD Bukit Jaya untuk kegiatan repanting pada masa datang.

2. Petani belum mengetahui dan belum merencanakan alternatif kegiatan ekonomi sebagai sumber pendapatan rumah tangga selama tanaman sawit yang diremajakan belum menghasilkan.

3. Petani belum memiliki rencana pembiayaan peremajaan kebun kelapa sawit.

4. Kelompok tani belum memiliki rencana aksi peremajaan kebun kelapa sawit.

5. KUD Bukit Jaya belum memiliki rencana untuk memfasilitasi kelompok tani melakukan peremajaan kebun kelapa sawit.

6. Kegiatan peremajaan tanaman kelapa sawit mendesak untuk dilaksanakan karena umur tanaman sudah tidak ekonomis lagi.

Solusi yang ditawarkan untuk menyelsaikan masalah:

1. Perlu memberdayakan koperasi dengan pendekatan partisipatif agar dapat berfungsi kembali melalui pendampingan manajemen koperasi petani;

2. Perlu menyusun rencana kegiatan ekonomi alternatif (diversifikasi usaha) sebagai sumber pendapatan rumah tangga petani sawit selama tanaman belum menghasilkan.

3. Memikirkan dan menyusun rencana pembiayaan peremajaan kebun kelapa sawit.

4. Menyusun rencana aksi peremajaan kebun kelapa sawit bersama kelompok tani. 
5. Menyusun rencana kegiatan KUD Bukit Jaya agar dapat berfungsi dan memfasilitasi kelompok tani melakukan peremajaan kebun kelapa sawit.

6. Perlu membangun dan memelihara kelembagaan perkebunan kelapa sawit yang terbuka, dipercaya dan bertanggung jawab di Kabupaten Dharmasraya.

7. Perlunya peningkatan kapabilitas sumberdaya manusia (stakeholders) pembangunan perkebunan dan pembangunan wilayah perdesaan dengan pendekatan partisipatif dalam rangka pembangunan berkelanjutan.

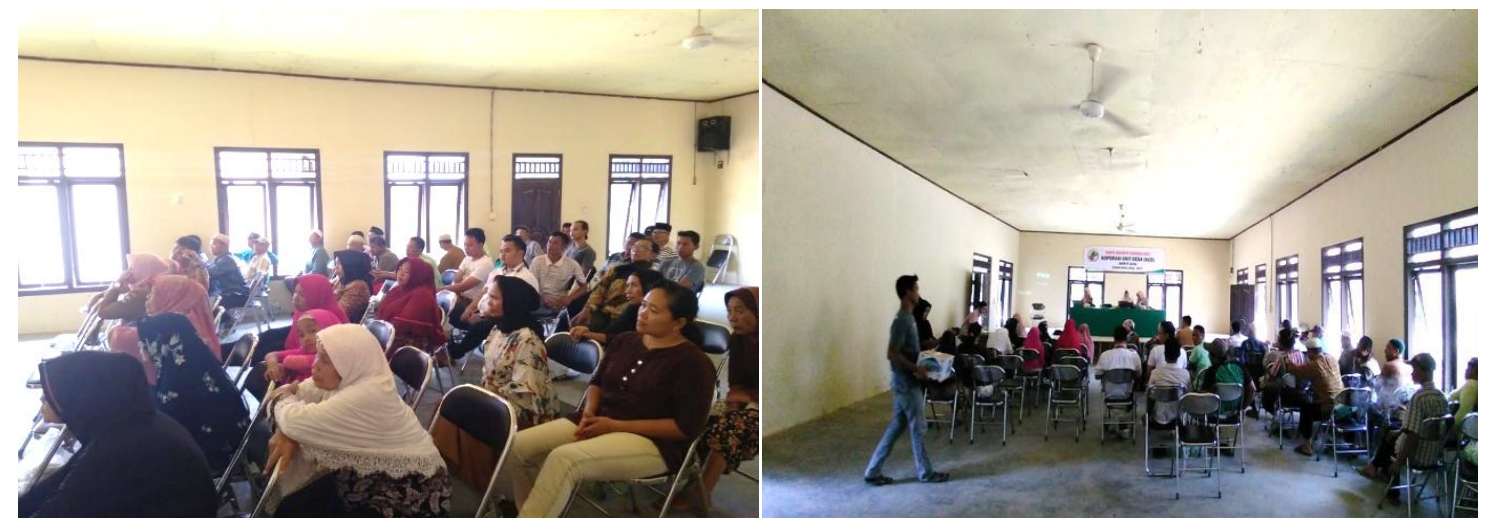

Gambar 1. Suasana Fokus Group Dsicussion (FGD) Persiapan Replanting Kelapa Sawit di Ruang Pertemuan KUD Bukit Jaya

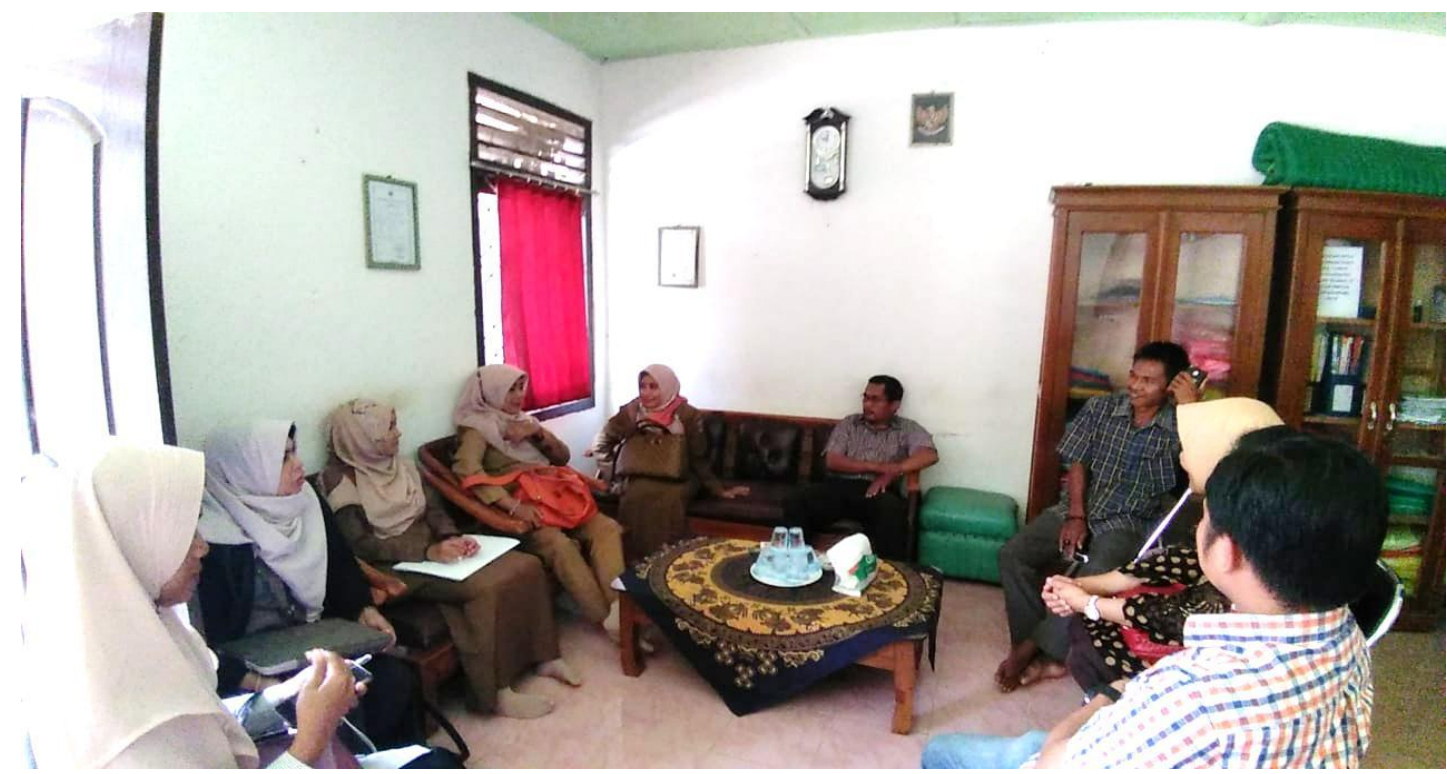

Gambar 2. Wawancara dengan Tim Bappeda Kabupaten Dharmasraya dan KUD Bukit Jaya sebagai Lanjutan FGD 


\section{Kesiapan Petani untuk Replanting}

KUD Bukit Jaya disiapkan untuk dapat memenuhi persyaratan pendanaan dari sumber pembiayaan Badan Pengelola Dana Perkebunan Kelapa Sawit (BPDPKS). Dari semua persyaratan administrasi yang dibutuhkan, ada yang dapat dipenuhi petani sebagai anggota KUD, Pengurus KUD, dan Dinas atau instansi teknis pemerintah atau pemerintah kabupaten Dharmasraya. Kondisi saat ini belum siap untuk replanting dari segi pembiayaan karena pencairan dana Asuransi Idapertabun belum terealisasi.

Tabel. Rencana Aksi Replanting Kelapa Sawit KUD Bukit Jaya - Kabupaten Dharmasraya

\begin{tabular}{|c|c|c|c|c|}
\hline No. & Kegiatan & Deskripsi & Pelaksana & Pendamping \\
\hline 1 & $\begin{array}{l}\text { Pengajuan surat } \\
\text { permohonan }\end{array}$ & $\begin{array}{l}\text { Permohonan dari kelompok setelah } \\
\text { melengkapi persyaratan administrasi } \\
\text { untuk mendapatkan dana BPDPKS. } \\
\text { KUD Bukit jaya akan diprioritaskan } \\
\text { untuk tahun } 2019 .\end{array}$ & KUD Bukit Jaya & $\begin{array}{l}\text { Tim Replanting } \\
\text { Kabupaten }\end{array}$ \\
\hline 2 & $\begin{array}{l}\text { Sosialisasi model } \\
\text { replanting kelapa } \\
\text { sawit }\end{array}$ & $\begin{array}{l}\text { Sosialisasi replanting kepada petani } \\
\text { secara detail teknis budidaya dan } \\
\text { pembiayaan. Model yang disepakati } \\
\text { adalah model kemitraan dengan } \\
\text { Perusahaan inti. Untuk itu perlu } \\
\text { dibuat kesepakatan baru, karena } \\
\text { sudah lama tidak bekerjasama. }\end{array}$ & $\begin{array}{l}\text { Dinas Perkebunan } \\
\text { Kabupaten }\end{array}$ & $\begin{array}{l}\text { Tim Replanting } \\
\text { Kabupaten }\end{array}$ \\
\hline 3 & $\begin{array}{l}\text { Menyusun rencana } \\
\text { biaya }\end{array}$ & $\begin{array}{l}\text { menyusun rencana kebutuhan dan } \\
\text { pembiayaan peremajaan perkebunan } \\
\text { kelapa sawit (RKP3KS) }\end{array}$ & KUD Bukit Jaya & $\begin{array}{l}\text { Dinas Pertanian } \\
\text { Kabupaten }\end{array}$ \\
\hline 4 & $\begin{array}{l}\text { Peta Lokasi kebun } \\
\text { dan kavling dengan } \\
\text { koordinat }\end{array}$ & $\begin{array}{l}\text { Peta lokasi kebun kelapa sawit } \\
\text { rakyat yang akan direplanting }\end{array}$ & KUD Bukit Jaya & $\begin{array}{l}\text { Dinas Pertanian } \\
\text { Kabupaten }\end{array}$ \\
\hline 5 & $\begin{array}{l}\text { Realisasi Asuransi } \\
\text { Idapertabun }\end{array}$ & $\begin{array}{l}\text { Pencairan dana asuransi sebagai } \\
\text { dana tambahan / tabungan, saat ini } \\
\text { sedang menunggu pencairan setelah } \\
\text { persyaratan dilengkapi }\end{array}$ & $\begin{array}{l}\text { PT Asuransi } \\
\text { Bumi Putra }\end{array}$ & $\begin{array}{l}\text { Dinas Koperasi } \\
\text { Kabupaten }\end{array}$ \\
\hline 6 & $\begin{array}{l}\text { Pengajuan usulan } \\
\text { pendanaan }\end{array}$ & $\begin{array}{l}\text { Mengajukan usulan dana bantuan } \\
\text { BPDPKS dan akan diprioritaskan } \\
\text { untuk usulan tahun } 2019\end{array}$ & $\begin{array}{l}\text { Tim Replanting } \\
\text { Kabupaten }\end{array}$ & $\begin{array}{l}\text { Bappeda Kabupaten } \\
\text { Dinas Perkebunan } \\
\text { Propinsi }\end{array}$ \\
\hline
\end{tabular}

\section{KESIMPULAN DAN SARAN}

Kegiatan pengabdian kepada masyarakat ini berkontribusi kepada terbangunnya kesadaran petani untuk melakukan peremajaan kebun kelapa sawit, tersusunnya rencana aksi peremajaan kebun kelapa sawit di tingkat kelompok tani, tersusunnya rencana kegiatan KUD Jaya dalam rangka menjalankan fungsinya dan memfasilitasi kelompok tani untuk kegiatan peremajaan kebun sawit, dan terwujudnya peremajaan kebun kelapa 
sawit melalui kegiatan kelompok tani dan KUD di Kecamatan Tiuman Kabupaten Dahramsaya.

Kontribusi yang lebih luas diharapkan KUD Bukit Jaya menjadi contoh kegiatan pemberdayaan petani dan koperasi perkebunan kelapa sawit untuk mewujudkan pembangunan perkebunan kelapa sawit berkelanjutan di Propinsi Sumatera Barat. Disamping itu, kegiatan ini juga membantu mempercepat terwujudnya pembangunan perkebunan kelapa sawit rakyat untuk pembangunan perkebunan kelapa sawit berkelanjutan, dan membangun kolaborasi perguruan tinggi, pemerintah, perusahaan, dan masyarakat petani kelapa sawit untuk pembangunan wilayah perdesaan yang lebih baik melalui pembangunan perkebunan berkelanjutan.

Rekomendasi yang dikeluarkan untuk rencana aksi replanting kebun kelapa sawit adalah sebagai berikut:

1. Pemerintah daerah yang telah membentuk tim khusus yakni tim re-planting kabupaten, akan terus didorong untuk merealisasikan program replanting di Dharmasraya. KUD Bukit Jaya adalah contoh KUD yang telah siap dan aktif untuk memulai program replanting kelapa sawit di kabupaten.

2. KUD memerlukan kepastian sistem re-planting dan tahapan yang jelas. Semua persyaratan akan dilengkapi dibawah bimbingan teknis Dinas Pertanian Kabupaten Dharmasraya untuk penyusunan Rencana Anggaran Biaya kelompok, termasuk menetapkan termin pembayaran sesuai TBM 1-TBM3 dan TM4-TM7, dst.

3. Dinas Pertanian Kabupaten Dharmasraya perlu memberikan sosialisasi kejelasan prosedur dan tahapan re-planting. Memperkenalkan model - model replanting, dan menetapkan pilihan yang sesuai dengan kondisi petani. Intercropping (menanam tanaman sela) disarankan untuk memenuhi ekonomi rumah tangga petani sebelum tanaman menghasilkan.

Diharapkan dengan penanaman ulang kelapa sawit yang telah melewati umur produktif secara ekonomis, pembangunan perkebunan kelapa sawit di Sumatera Barat, khususya Kabupaten Dharmasraya dapat terlaksana secara berkelanjutan. Perkebunan merupakan sumber mata pencaharian utama masyarakat di Kabupaten, sehingga perlu direncanakan dengan baik pengelolaan perkebunan di masa datang. Untuk itu, Koperasi perlu ditumbuhkan kembali sebagai soko guru perekonomian rakyat. Selain itu juga perlu membangun dan mengembangkan kembali kerjasama koperasi dengan mitra usaha, baik dengan perusahaan inti atau mitra baru dalam hubungan yang terbuka dan kerjasama yang saling menguntungkan.

\section{UCAPAN TERIMAKASIH}

Kegiatan Pengabdian Kepada Masyarakat ini didanai dengan Kontrak Pengabdian Program Pascasarjana Universitas Andalas, No. 10/UN.16.16/PM.PPPUD/PP/2018 tanggal 27 Juni 2018. Untuk itu kepada Direktur Pascasarjana Universitas Andalas diucapkan terimakasih. 


\section{DAFTAR PUSTAKA}

Direktorat Jenderal Perkebunan. 2014. Statistik Perkebunan Indonesia Komoditas Kelapa Sawit 2013-2015. Direktorat Jenderal Perkebunan, Jakarta.

Hatta, M. 1998. Membangun Ekonomi Indonesi. Inti Idayu Press, Jakarta.

Saragih. 2000. Membangun Koperasi Pertanian Berbasis Anggota. repository.ipb.ac.id/handle/ 123456789/45077.

Syarfi., W. Ira, dan M. Noer. 2017. Penguatan Kelembagaan Petani Sawit dalam Kegiatan Replanting di Kabupaten Dharmasra 